\title{
Alguns Parâmetros da Criticidade e da Complexidade em Propostas de Aulas Socioambientais Presenciais e Remotas
}

\section{Parameters of Criticality and Complexity in Proposed Face-to-face and Remote Socio-Environmental Classes}

\author{
Fabrício Masaharu Oiwa da Costa, Carla Sarmento Santos, Giselle Watanabe
}

Palavras-chave

Criticidade;

Complexidade;

Ensino de Ciências;

Paulo Freire.
Resumo Os conceitos científicos escolares tratados a partir de uma perspectiva estritamente tradicional pouco privilegiam as relações entre os diversos conhecimentos assim como as atuais condições da escola, tais como as impostas pela pandemia. Diante deste cenário, nos parece fundamental buscar abordagens pautadas em preceitos de um conhecimento mais crítico e complexo. Nesse sentido, este artigo analisa a experiência ao produzir duas propostas de aulas para a escola pública tanto no contexto presencial quanto remoto. A intenção é analisar esses processos de produção a fim de indicar parâmetros que podem contribuir para um ensino mais próximo da realidade dos estudantes. Toma-se a Análise Textual Discursiva para analisar as ideias presentes nas produções e nas anotações no Diário do Professor. Dos resultados, nota-se que a proposição de um conjunto de aulas mais crítica e complexa pode ser viável ao (i) estabelecer maiores aproximações com as realidades dos estudantes e promover o engajamento e autonomia dos sujeitos em espaços que vão além da escola (no caso remoto, os usos críticos dos meios virtuais; no caso presencial, a aproximação com a comunidade); e (ii) contemplar os contextos socioeconômicos e conceitos escolares pautados em abordagens mais abertas e dinâmicas. 
Keywords Abstract Teaching science at school using strictly traditional methods

Criticality; does not provide relations between different kinds of knowledge

Complexity; nor favor the current conditions imposed by the pandemic. In this Science Teaching; scenario, it seems essential to look at approaches based on precepts

Paulo Freire. of a more critical and complex knowledge. In this regard, this article analyzes the experience with two proposals for public school classes, both for face-to-face and remote contexts. Our goal is to analyze the process of both experiences, in order to indicate parameters that may contribute to an education closer to students' reality. Discursive Textual Analysis is used to study the ideas present in the productions and notes from the Teacher's Diary. From the results, it is possible to highlight that the proposition of a set of more critical and complex classes may be feasible (i) to establish bonds with students' reality and to promote the subjects' engagement and autonomy outside of school (in the remote modality, the critical use of virtual resources; when face-to-face, approaching the community); (ii) to consider socioeconomic contexts and school concepts based on more open and dynamic approaches.

\section{Introdução}

Discussões sobre questões sociais e ambientais são relevantes na contemporaneidade, em especial quando se coloca no centro do debate o caráter complexo e a sua proximidade à realidade dos sujeitos ${ }^{1}$. No contexto atual, essas discussões ampliaram-se com a declaração da Covid- $19^{2}$ como uma pandemia (World Health Organization, 2020). No Brasil, isso resultou na instabilidade não só nas esferas social e econômica, mas também na política, destacando-se aspectos questionáveis de tomadas de decisão pelo poder público. No que diz respeito à educação, a ausência de ações do estado contribuiu para agravar as desigualdades entre os estudantes do país. As escolas foram fechadas e as atividades presenciais foram suspensas. Esse cenário reforçou, do nosso ponto de vista, a necessidade de se oferecer espaços para que os estudantes pudessem lidar com situações de incertezas e riscos (Beck, 2010; Jacobi, 2012) e isso, por sua vez, implicaria relacionar o conhecimento escolar às outras distintas formas de conhecimento.

As pesquisas em ensino de ciências podem ajudar a incorporar os aspectos citados, incluindo aqueles que tratam da educação ambiental. Nossos estudos indicam certo potencial desses trabalhos para tratar questões abertas e dinâmicas como, por exemplo, o trabalho de Ribeiro e Kawamura (2014) que trata de temas controversos relacionados à educação ambiental e reforça a importância de reconhecer que aspectos da complexidade, inerentes às questões ambientais; o trabalho de Calafell e Banqué

1 Considera-se o gênero masculino respeitando as normas da língua portuguesa.

2 A pandemia foi decretada devido a doença causada pelo vírus SARS-CoV-2, também chamado de Novo Coronavírus (Covid-19). 
(2017) que trata da complexidade no âmbito da educação ambiental considerando-a um saber aberto e dinâmico; e o trabalho de Jacobi (2005) que traz reflexões sobre os riscos ambientais e tecnológicos e a inserção, no âmbito escolar, da educação ambiental a partir de um caráter mais complexo.

Nessa perspectiva, Morin (2007) salienta que o conhecimento se desenvolve como uma teia, composta por partes que não devem ser dissociadas para compreensão real do todo, de forma que cada interligação criada entre essas partes propicia uma teia maior e mais forte. Mostra-se, então, a necessidade de se pensar o mundo de maneira mais complexa e dinâmica, dando espaço ao pensamento complexo; assim, a complexidade permite analisar o conhecimento de forma semelhante a um sistema aberto. Segundo o autor, "conceber todo objeto e entidade como fechado implica uma visão de mundo classificadora, analítica, reducionista, numa causalidade unilinear” (Morin, 2007, p. 23).

O conhecimento científico escolar construído a partir desta perspectiva deve permitir aos estudantes o desenvolvimento da autonomia para serem capazes de interferir construtivamente em suas realidades. Isso se dá ao promover uma formação mais complexa pautada por um olhar crítico (Freire, 1967; Freire, 1976; Freire, 2016), implicando numa educação na qual o estudante é protagonista na construção de seu próprio conhecimento, considerando aspectos históricos, sociais e culturais, baseados inclusive, em sua visão de mundo. Nesse sentido, os elementos a serem trabalhados em sala de aula podem ser contextualizados, considerando o posicionamento dos estudantes e as suas relações com o mundo. Com isso, as abordagens pautadas na criticidade freireana auxiliam na compreensão do papel dos indivíduos, enquanto cidadão numa sociedade em constante transformação. Para Freire (1968), a realidade

(...) social, objetiva, que não existe por acaso, mas como produto da ação dos homens, também não se transforma por acaso. Se os homens são os produtores desta realidade e se esta, na "inversão da práxis" se volta sobre eles e os condiciona, transformar a realidade opressora é tarefa histórica, é tarefa dos homens. Ao fazer-se opressora, a realidade implica na existência dos que oprimem e dos que são oprimidos. Estes, a quem cabe realmente lutar por sua libertação juntamente com os que com eles em verdade se solidarizam, precisam ganhar consciência crítica da opressão, na práxis desta busca. (Freire, 1968, p. 39).

A escola, como local privilegiado para o desenvolvimento de um conhecimento sistematizado, pode desempenhar esse papel de tomada de consciência dos elementos que compõem a realidade. Isso se torna possível quando, no contexto escolar, a busca pela complexidade e pela realidade dos sujeitos sugere propor ações que se afastam da concepção utilitarista do meio; do conhecimento implícito frente ao explícito; do foco no perceptivo, evidente e imediato; de relações causais muito simples; das perspectivas únicas, absolutas, fechadas e unidimensionais (García, 2004), permitindo estabelecer uma visão de ciência menos simplificadora. Busca-se, portanto, propor atividades temáticas abertas, dinâmicas e complexas, voltadas, por exemplo, à questão socioambiental. Essa busca aponta para a necessidade de estudar uma relação harmônica e horizontal entre os 
seres vivos. Entende-se que essa relação harmônica entre sujeito e ambiente requer uma busca constante por meios de usufruir da terra respeitando seus limites. Isso, implica, por exemplo, em promover mudança no comportamento de consumo, favorecendo aquela que seja mais local ou pautada em preceitos da permacultura na produção de alimentos (García, 2021).

Ao considerar uma perspectiva mais crítica e complexa, nota-se a necessidade de trabalhar as situações problemas vinculadas às escalas (relação entre micro e macro), aos sistemas e às dimensões. Por exemplo, nas aulas de ciências, ao se tratar de conceitos que vão de células (perspectiva microscópica) para níveis de organização dos seres vivos (perspectiva macroscópica), há abordagens sobre as possíveis interações nos sistemas, permitindo compreender as relações interna e entre sistemas articuladas com interações e interferências. Aspectos da permacultura, citados anteriormente, também podem contribuir para essa discussão. Conforme afirmam Mollison e Slay (1998), ao abandonar a ideia da superioridade humana sobre o mundo natural, é possível dar espaço para analisar criticamente a noção de superioridade e independência enraizada na concepção tradicional antropocêntrica da relação homem-natureza. Por exemplo, as hortas construídas nos espaços escolares podem ser entendidas como uma ferramenta para a reflexão acerca desses preceitos, além de apresentar potencial para o desenvolvimento de pensamento mais crítico. Rodríguez-Marín, Fernández-Arroyo \& Díaz (2015) afirmam que o trabalho com hortas pode "ajudar a compreender quais são os limites do crescimento e quais são as práticas agrícolas ecológicas que podem facilitar a autoprodução e autoconsumo com desempenho máximo de energia, o mínimo desperdício de recursos e a produção mínima de resíduos” (p. 40).

Diante dessas preocupações - a realidade enfrentada pela escola e a busca de uma formação mais complexa e crítica - esse artigo analisa o processo de construção de duas propostas de aulas denominadas (i) Horta escolar e dinâmica dos ciclos e (ii) Células e sistemas, visando indicar alguns parâmetros da complexidade e da criticidade, retirados tanto da experiência no ensino presencial (i) quanto remoto (ii), que podem contribuir para uma formação mais próxima da realidade dos alunos, na qual estão presentes aspectos do risco e das incertezas. O risco e a incerteza estão relacionados aos fatores sociais e ambientais e imbricados ao desenvolvimento técnico econômico, que de acordo com Beck (2010), podem apresentar um caráter global com potencial dano, tais como as questões que envolvem problemas socioambientais (poluição ar, solo, terra etc.) e o aumento do aquecimento global. Além disso, as situações de risco também podem apresentar um caráter mais local, e uma certa individualidade. Destaca-se que ambas propostas foram aplicadas em uma mesma escola pública.

\section{Fundamentação teórica: aspectos para um ensino mais crítico e complexo}

$\mathrm{Na}$ perspectiva freireana, a questão da criticidade volta-se principalmente à problematização dos fatos da realidade, pois são neles que residem as contradições normalizadas. Durante toda a vida essas contradições surgem, e como parte da tomada 
de consciência, é necessário que sejam adequadamente problematizadas e organizadas. Isso se torna possível ao considerar que o conhecimento não está pronto, mas é uma construção constante, por conta da incompletude inerente ao ser-humano. Essa percepção da própria inconclusão é crucial para a busca de um pensamento crítico, pois ao se tomar consciência de algum elemento, não se absorve todo conhecimento relacionado a ele, mas aprende-se a percebê-lo numa nova perspectiva, consequentemente, isso mostra a importância de se introduzir conhecimentos não espontâneos (científicos escolares) para que o estudante possa ampliar seus horizontes.

Para Freire (1979), essa tomada de consciência é uma etapa da conscientização. Ou seja, parte-se do entendimento da realidade direta até a compreensão crítica da mesma como objeto cognoscível. Em outras palavras, a conscientização é a tomada de consciência que se aprofunda, é o desenvolvimento crítico implicando na ação (Costa, 2019), que ultrapassa o discurso, transpondo as ideias para o mundo real. Com isso, a diferenciação entre conscientização e tomada de consciência reside no processo de desenvolvimento e valorização dos saberes, conhecimentos e ações. Percebe-se então, a importância de que os conhecimentos escolares não se restrinjam ao campo das ideias, reverberando também na ação no contexto vivido.

Essa reflexão remete a uma educação que se origina nas escolhas conscientes no processo educativo. Em outras palavras, Freire (2014) discute a não neutralidade, apontando para as escolhas que refletem num processo contínuo de trocas e relações internas e externas ao ambiente escolar. Com isso, apenas quando o docente considera essa gama significativa de visões e posturas é que pode conceber uma prática educativa crítica no sentido de formar cidadãos. Segundo Freire e Freire (2014)

Falamos em ética e em postura substantivamente democrática porque, não sendo neutra, a prática educativa, a formação humana, implica opções, rupturas, decisões, estar com e pôr-se contra, a favor de algum sonho e contra outro, a favor de alguém e contra alguém. E é exatamente este imperativo que exige a eticidade do educador e sua necessária militância democrática a lhe exigir a vigilância permanente no sentido da coerência entre o discurso e a prática. Não vale um discurso bem articulado, em que se defendem que o direito de ser diferente e uma prática negadora desse direito. (Freire \& Freire, 2014, p. 45)

Ao considerar a perspectiva freireana como orientadora de atividades educativas é incoerente a imposição de determinadas visões. Há de se promover, portanto, a vigilância constante da própria prática, no sentido de que, ao mostrar uma visão, o docente esteja apto a ouvir e dialogar com as diferentes visões e cultivar o respeito, pois haverá um conjunto de distintas perspectivas, algumas mais ingênuas e outras mais críticas, enriquecendo-se umas às outras de forma dialógica. O resultado se mostrará fora da escola, lugar onde os estudantes poderão ser confrontados em diferentes situações e poderão agregar em seus posicionamentos elementos mais críticos e complexos.

$\mathrm{O}$ respeito que se estabelece na relação professor-aluno só ocorre quando o docente assume que não é o detentor do saber. Nesse processo, ele precisa estar aberto a aprender, atuando como um "educador-educando"; e estimular o estudante para que 
atue como sujeito, atuando como um "educando-educador". Essa dialogia permite ao docente identificar e aprender sobre a comunidade local, no sentido de procurar espaços para promover uma educação libertadora e problematizadora nessa realidade. Para Freire (1996), a liberdade se dá pelo entendimento das condições e possibilidades que limitam nossa atuação no mundo; e a autoridade implica no trabalho com os discentes como orientador sobre a atuação diante desses limites. A libertação, enfim, visa romper limites sociais injustos e sem sentido.

Essa libertação é possível à medida que se toma consciência que as sociedades contemporâneas estão imersas numa lógica de hiperconsumo e pautadas por um crescimento econômico exacerbado. Trata-se do crescimento pelo crescimento (Latouche, 2009) que promove ações incompatíveis com a finitude dos recursos naturais quando usados de maneira agressiva. Essa lógica é questionada pelo Decrescimento, que tem como meta "enfatizar fortemente o abandono do objetivo do crescimento ilimitado, objetivo cujo motor não é outro senão a busca do lucro por parte dos detentores do capital, com consequências desastrosas para o meio ambiente e portanto para a humanidade" (Latouche, 2009, p. 4). Em essência, o decrescimento está ligado a uma visão heterogênea de culturas, ao respeito e a sensatez de não subjugar a natureza e outras formas de interpretar o mundo. Assim, a visão homogênea de desenvolvimento socioeconômico parte de uma perspectiva enfraquecida e fragmentada distante da complexidade do real, perspectiva essa discutida por Leff (2009) como um problema a ser superado a fim de se desenvolver o saber ambiental - que propõe, dentre outros aspectos, a desconstrução do crescimento sem limites - e a complexidade ambiental - sendo ela "o produto da intervenção do pensamento no mundo" (Leff, 2009, p. 418). Para Morin (2007), esse pensamento se relaciona com os princípios de recursão organizacional, dialógico e hologramático, tendo em vista que a interação entre conceitos aparentemente antagônicos, como a produção e a limitação dos recursos, possa ter em sua essência características de causa/efeito e parte/todo num sistema global e dinâmico. Para esses autores, o pensamento complexo permite alterar os paradigmas que ocasionam em mudanças socioambientais, levando à reconstrução de relações entre os seres, e no caso dos estudantes, impactando em sua visão de mundo.

Esses aspectos apontam para algumas ações no contexto social, dentre elas a permacultura que, por sua vez, se baseia em três pilares éticos (Mollison \& Slay, 1998, p. 15), sendo eles: (i) cuidado com o planeta Terra, o qual diz respeito à valorização da natureza desarticulada de qualquer valor comercial; (ii) cuidado com as pessoas; e (iii) cuidado com a distribuição do excesso de tempo, dinheiro e materiais para atingir tais fins. Apresenta, dentre outros aspectos, uma forma de tratar a problemática em relação ao esgotamento energético, assunto em geral ressaltado quando se discute sobre as consequências do modelo de consumo das sociedades modernas. A permacultura configura-se, então, como um sistema que estabelece umalógica de organização energética cíclica e autossuficiente, a partir de mecanismos de policultura e reaproveitamento de alimentos. Em outras palavras, a permacultura ressignifica as relações entre terras, 
plantas, animais e infraestrutura e trata, sobretudo, da forma como os seres humanos se posicionam sobre o terreno; está alinhada às ideias do decrescimento, entendendo a relação entre homem e natureza enquanto parte de um sistema aberto, dinâmico e complexo, pautados nos elementos da complexidade.

Os pressupostos discutidos até aqui influenciam o processo de ensinagem no que tange buscar outras formas de estruturar o conhecimento e por ações que levem a

[...] nos aproximar dos problemas socioambientais da mesma maneira que a ciência, ao desenvolver um ideário coletivo mais "complexo", baseado na investigação de problemas, na criatividade, no pensamento crítico e complexo, no conhecimento científico e no trabalho cooperativo. Com isso é possível aumentar nossa capacidade de resiliência (e a complexidade do sistema). Em particular, propomos, no âmbito de uma aproximação da perspectiva da complexidade, uma revalorização do papel da ciência e da tecnologia adaptadas a uma sociedade em decrescimento, uma vez que dar proeminência ao conhecimento cotidiano e as ideias míticas supõe reduzir a resiliência da população no momento em que tem que enfrentar problemas como a mudanças climáticas ou o possível esgotamento de recursos naturais. (Díaz \& Watanabe, 2019, p. 26-27)

$\mathrm{O}$ ensino nesta perspectiva supõe uma mudança na forma de compreender o universo, na reorganização do saber e numa nova maneira de dirigir a indagação sobre nosso entorno, com a contínua busca das articulações e das interdependências entre os conhecimentos, favorecendo uma atitude pautada pela complementaridade, antirreducionista e relativizadora, que foge do dogmatismo e do uso de receitas simplificadoras, que admite a existência das incertezas, paradoxos e contradições. Essa concepção sistêmica, ao descrever o mundo entendido como um sistema de sistemas, pauta-se por componentes da realidade que interagem (anéis recursivos, causalidade circular, causa-efeito etc.), requerem atitudes mais críticas frente aos efeitos destrutivos da visão simplificadora para as relações entre os humanos e o meio, assim como, capacitam para a ação, para a participação na gestão do meio e da própria vida, superando a dicotomia entre os especialistas que planejam e os novatos que consomem o planejado (García, 2004).

Uma forma de contemplar elementos que promovam essa formação mais crítica, reflexiva e complexa aparecem nas Dimensões (Watanabe-Caramello \& Kawamura, 2014; Watanabe, 2021) que vão tratar da formação do indivíduo (Dimensão Educacional); das ações em sala de aula (Dimensão Ensino-Aprendizagem); e da abordagem de situações dinâmicas e longe do equilíbrio (Dimensão Epistemológica). Destaca-se que essas dimensões foram organizadas a partir da ideia de que a natureza do conhecimento é aberta e dinâmica. A Dimensão Educacional preconiza uma formação na qual o estudante constrói o seu conhecimento, pautado pelo conceito da reflexividade em que se projeta sujeitos auto-confrontadores, capazes de agir diante de situações imprevisíveis (Beck, 2010); pela atitude antirreducionista que rejeita um discurso dogmático, sendo capaz de lidar com as incertezas, paradoxos e contradições (Morin, 2007); pela 
complementaridade, sendo capaz de lidar com as trocas, que aceita negociar, estabelecer conexões e trabalhar em diferentes perspectivas (García, 2004) e pelo desenvolvimento da visão de mundo e tomada de consciência dos elementos da realidade, para compreensão e transformação (Freire, 1968). A Dimensão Ensino-Aprendizagem preocupa-se com os espaços de ação na escola, implicando em considerar a realidade da escola e dos alunos; em trabalhar com temas abertos e complexos capazes de mobilizar conteúdos científicos escolares, culturais, sociais etc.; em construir um conhecimento escolar autônomo e com suas próprias dinâmicas; em propor aulas que considerem aspectos como conceito metadisciplinar, hipóteses de transição, processo de investigação temática, havendo grande preocupação em incorporar elementos da realidade, principalmente pautado por uma perspectiva crítica e complexa. A Dimensão Epistemológica considera a complexidade nas Ciências Naturais, buscando contemplar os conhecimentos como o acaso; o caos; a ordem-desordem; as conexões, as relações e inter-relações; as incertezas e os riscos; a seta do tempo, acontecimentos e irreversibilidade; que o todo não se reduz à soma das partes, mas apresenta propriedades que as partes não têm; sistemas abertos e dissipativos; tempo limitante e construtivo; limite dos sistemas vivos e ciclo da vida etc., nos quais incorporam a importância do conhecimento científico escolar como um conhecimento sistematizado e que se afasta de uma visão única de ciência e de verdades absolutas. A Figura 1 traz alguns dos aspectos discutidos nesta seção.

Figura 1. Quadro apresentando aspectos que caracterizam a criticidade e complexidade

\begin{tabular}{|l|l|}
\hline \multicolumn{2}{|l|}{ Aspectos que caracterizam a criticidade e a complexidade } \\
\hline Complexidade & Criticidade \\
\hline - Conhecimento se desenvolve como uma teia & - Problematização dos fatos da realidade (Freire, \\
(Morin, 2007) & $1968)$ \\
- A importância de compreender a relação entre & - Tomada de consciência dos elementos que \\
micro e macro, sistemas e dimensões & compõem essa realidade \\
- Abandono da ideia da superioridade humana & - Diálogo entre as diferentes visões e cultivo do \\
sobre o mundo natural & respeito (Freire \& Freire, 2014) \\
- Combate às ações incompatíveis com a finitude & - Ética ao assumir o compromisso social com \\
dos recursos naturais quando usados de maneira & diferentes realidades. \\
agressiva & - Mudança na visão de mundo. \\
- Concepção sistêmica & - Transformação Social através da Ação-Reflexão- \\
- (Dimensão Educacional); (Dimensão Ensino- & Ação \\
Aprendizagem); (Dimensão Epistemológica) & \\
\hline Fonte: elaboração própria dos autores.
\end{tabular}




\section{Aspectos metodológicos: os caminhos da pesquisa}

Este trabalho é parte de um projeto que investiga elementos para promover a articulação entre aspectos da criticidade e da complexidade na questão socioambiental, de modo a levar discussões contemporâneas às escolas através de propostas de aulas que refletem o trabalho com problemas abertos e dinâmicos. Conta com as colaborações do Grupo de Ensino de Ciências e suas Complexidades (GrECC), de professores da escola básica (de biologia, física e matemática do ensino médio; de ciências, língua portuguesa e artes do ensino fundamental), da coordenadora pedagógica da escola básica e de pesquisadoras da Espanha. O projeto tem apoio financeiro do Ministério da Ciência, Tecnologia, Inovações e Comunicações e do Conselho Nacional de Desenvolvimento Científico e Tecnológico ${ }^{3}$.

Em específico, neste texto discutem-se duas propostas de aulas aplicadas na escola básica parceira, situada numa região vulnerável de São Paulo. A primeira, trata-se de uma proposta presencial sobre o tema Horta escolar e dinâmica dos ciclos, envolvendo 46 estudantes dos sextos e sétimos anos do ensino fundamental, os quais foram divididos em grupos e delegadas as tarefas de construção de hortas, preparo do espaço e pesquisa na sala de informática. Para esta proposta também contribuíram a comunidade externa (como proprietários de estabelecimentos locais que doaram materiais) e agentes escolares (merendeira e representantes do grêmio). A segunda proposta, produzida para a mesma escola mas em formato remoto, tratou do tema Células e sistemas. Ela foi aplicada em cinco turmas do sexto ano, totalizando 109 estudantes participantes. A interação ocorreu quase que exclusivamente pelo aplicativo whatsapp. Para cada turma havia um grupo no aplicativo, estando presentes estudantes ou seus responsáveis, coordenadora pedagógica e docentes das diferentes disciplinas escolares.

Tomando como fundamento o princípio dialógico (Freire, 1968) e considerando o processo como dinâmico e complexo (García, 2004), a construção das propostas de aulas contou com a participação ativa dos professores e dos pesquisadores que propunham reformulações constantes, seja devido ao contexto da pandemia ou pela necessidade de articulações conceituais mais adequadas para o público em questão. Vale ressaltar que as decisões entre os diferentes sujeitos foram tomadas nas reuniões presencial ou virtual. Tanto os momentos de organização e planejamento quanto os de implementação e ação geraram subsídios para as reconstruções das propostas, salientando o processo dinâmico já no formato de produção de aulas. Para analisar o processo de construção e os dos resultados de sua aplicação, visando identificar elementos da complexidade e da criticidade, tomou-se: (i) os dados obtidos a partir do acompanhamento do processo de construção das propostas de aulas presencial e remota, organizados no Diário do Professor (Pórlan, 1997); e (ii) os dados presentes nas produções dos estudantes ao realizar as atividades presenciais da proposta Horta escolar e dinâmica dos ciclos e as atividades remotas da proposta Células e sistemas. Na Figura 2, a partir dos relatos descritos no Diário do Professor, são indicados alguns momentos durante o processo de construção e aplicação das propostas em que os dados foram coletados.

3 Chamada 05/2019, processo no 440369/2019-3. Salienta-se que este projeto foi submetido e aprovado pelo Comitê de Ética em Pesquisa (CEP) da Universidade Federal do ABC, através da Plataforma Brasil, registrado sob o número CAAE 25676219.8.0000.5594. 
Figura 2. Quadro com alguns momentos durante o processo de construção e aplicação das propostas em que os dados foram coletados

\begin{tabular}{|c|c|c|c|}
\hline Proposta & \multicolumn{2}{|c|}{ Proposições nas reuniões } & Ações na escola \\
\hline $\begin{array}{l}\text { (Presencial) } \\
\text { Horta escolar } \\
\text { e Dinâmica } \\
\text { dos ciclos }\end{array}$ & $\begin{array}{l}\text { - Encontro presencial } \\
\text { entre a direção, } \\
\text { coordenação, corpo } \\
\text { docente e GrECC para } \\
\text { tratar das possibilidades } \\
\text { de atuação na escola. } \\
\text { - Apresentação das } \\
\text { ideias. } \\
\text { - Diálogo com } \\
\text { os profissionais } \\
\text { responsáveis pela } \\
\text { produção de merenda, } \\
\text { estudantes do } \\
\text { grêmio estudantil e } \\
\text { comunidade externa. }\end{array}$ & $\begin{array}{l}\text { - Definição dos conceitos } \\
\text { escolares a serem estudados. } \\
\text { - Seleção das turmas } \\
\text { participantes. } \\
\text { - Planejamento das aulas } \\
\text { em parceria com docentes e } \\
\text { GrECC. } \\
\text { - Distribuição de tarefas }\end{array}$ & $\begin{array}{l}\text { - Conversa entre } \\
\text { estudantes e } \\
\text { pesquisadores, visando } \\
\text { buscar elementos da } \\
\text { realidade dos sujeitos. } \\
\text { - Arrecadação } \\
\text { de materiais na } \\
\text { comunidade. } \\
\text { - Construção da horta. } \\
\text { - Estudo e pesquisa } \\
\text { teórica no laboratório } \\
\text { de informática sobre as } \\
\text { plantas cultivadas nas } \\
\text { hortas (produção de } \\
\text { relatórios e criação do } \\
\text { sistema QRcode). }\end{array}$ \\
\hline $\begin{array}{l}\text { (Remota) } \\
\text { Células e } \\
\text { Sistemas }\end{array}$ & $\begin{array}{l}\text { - Encontro remoto } \\
\text { entre corpo docente, } \\
\text { coordenadora } \\
\text { pedagógica e GrECC } \\
\text { para tratar das } \\
\text { possibilidades de } \\
\text { atuação no contexto da } \\
\text { pandemia. }\end{array}$ & $\begin{array}{l}\text { - Definição dos conceitos } \\
\text { escolares estudados e } \\
\text { formato mais curto de aulas. } \\
\text { - Seleção das turmas } \\
\text { participantes e decisão } \\
\text { sobre as plataformas virtuais } \\
\text { utilizadas. } \\
\text { - Produção de podcast para } \\
\text { facilitar entendimento das } \\
\text { tarefas. }\end{array}$ & $\begin{array}{l}\text { - Encaminhamento } \\
\text { das propostas de aula } \\
\text { por meio do whatsapp, } \\
\text { principalmente. }\end{array}$ \\
\hline
\end{tabular}

Fonte: elaboração própria dos autores.

A partir dos dados obtidos (i) e (ii) e dos relatos/ indicações presentes da Figura 1, foram analisados considerando os preceitos da Análise Textual Discursiva (ATD) (Moraes \& Galiazzi, 2007). Na ATD o pesquisador aprofunda o material analisado e aumenta seu grau de compreensão. Para este trabalho, o corpus é formado pelas produções dos alunos e registros das duas propostas de aulas organizados no Diário do Professor. Para a análise, foram seguidos os processos: unitarização, que implica na fragmentação de trechos do processo de construção, das reuniões e das questões conceituais de cada proposta; identificação das unidades de significado que emergem do processo de unitarização; categorização em que se estabelece relações entre as unidades constituintes, agrupando em conjuntos mais complexos e críticos; processo de comunicação, que consiste na elaboração de metatextos que relacionam os principais elementos conceituais que caracterizam os referenciais nas dimensões, e que abordam a 
discussão da temática de aulas de ciências a partir de uma perspectiva da criticidade e da complexidade. As seguintes categorias foram encontradas: (a) aspectos de organização das atividades considerando as realidades dos sujeitos; e (b) os aspectos conceituais que podem promover abordagens mais abertas e dinâmicas. Os metatextos foram construídos alicerçados em ações presenciais e remotas que organizaram o processo, assim como os conceitos e as atividades elencados nas aulas, que relacionam os aspectos encontrados em criticidade e complexidade presentes nos referenciais teóricos sintetizados na Figura 1.

\section{Resultados e Discussões}

Como resultado descrevem-se os processos de construção das propostas, apontando os espaços nos quais ganham destaque aspectos da criticidade e da complexidade. Especificamente, a partir das categorias encontradas (a) e (b), primeiramente descrevem-se os processos de construção e aplicação da proposta indicando os espaços acima relatados e, em um segundo momento, sistematizam-se os principais parâmetros encontrados nas duas realidades estudadas (presencial e remota).

\section{O processo de construção e aplicação da proposta de aulas presenciais - Horta escolar e dinâmica dos ciclos}

$\mathrm{Na}$ categoria (a), que envolve aspectos de aproximação com a realidade, a proposta de aulas sobre Horta Escolar e dinâmica dos ciclos contou com seis reuniões presenciais além de dois momentos com os estudantes para a construção das hortas e da pesquisa na sala de informática da escola. A primeira reunião ocorreu entre os pesquisadores junto à diretora da escola para definir aspectos em relação à construção da horta e do espaço, a viabilidade do projeto, assim como sobre a disponibilidade de verba da escola e da possibilidade de apoio financeiro da prefeitura da cidade. A fim de que o projeto atendesse às demandas da escola, foi consultada a pessoa responsável pelo preparo da merenda e demais refeições. Com ela foram definidos os materiais a serem plantados para uso na cozinha, por exemplo, a "cebolinha" Allium schoenoprasum, o "coentro" Coriandrum sativum, "couve" Brassica oleracea, entre outros. Foram incluídas também duas Plantas Alimentícias Não Convencionais (PANC). A segunda reunião foi realizada com a coordenadora pedagógica para tratar do orçamento inicial. Discutiuse sobre a possibilidade de arrecadar caixotes de madeira que seriam descartados em "feiras livres" contando com a colaboração entre a comunidade do entorno da escola. $\mathrm{Na}$ terceira reunião a conversa se deu com a diretora para apresentação do orçamento. Neste momento o grêmio foi envolvido, assim como os familiares e a comunidade local, a fim de conseguir doações para a projeto (ferramentas, terra, adubo etc.). Durante Aula de Trabalho Pedagógico Coletivo (ATPC), ss docentes interessadas em participar do projeto foram acionadas. A quarta reunião foi realizada com o grêmio para delimitar as tarefas: busca ativa por materiais, conversa com professoras e coordenação. Na quinta reunião houve o primeiro contato, por intermédio de um aluno do grêmio, com o responsável 
que disponibilizou a terra, adubo e areia para a montagem da horta. Na sexta reunião foram definidas as responsabilidades, a saber: 1 . o grêmio ficou responsável por pintar e trabalhar no ambiente físico do espaço e mobilizar os demais alunos para concluir essa tarefa; 2. os funcionários da escola seriam os responsáveis pela instalação de pontos de luz; 3. as turmas envolvidas seriam responsáveis em construir as hortas, com ações em conjunto (reforçar as madeiras, forrar, envernizar, e preparar a base de sustentação dos caixotes, buscar materiais orgânicos, terra, areia, substrato e mudas/sementes, etc.).

Destaca-se que nessa proposta houve engajamento dos estudantes, mostrando preocupação com suas aprendizagens durante a construção das hortas. Os estudos foram realizados em dois grandes grupos. Cada um deles ficou responsável: (A) pela produção in locu da horta, incluindo limpeza e pintura do local onde foi instalada; (B) pelas atividades de divulgação dos conhecimentos que envolvem os conceitos científicos escolares. Em (A), ocorreu a organização e limpeza do espaço de construção e dos materiais a serem utilizados (caixotes); posteriormente houve a construção da horta, mantendo o envolvimento dos estudantes desde o preparo da terra aos transplantes das mudas e organização final do espaço. Em (B), paralelamente à atividade no espaço físico, uma outra turma de estudantes desenvolveu a atividade na sala de informática, a fim de realizar uma pesquisa sobre as plantas cultivadas na horta. A professora de ciências orientou a dinâmica da pesquisa, elaborando as seguintes perguntas a serem investigadas: (i) nome popular e nome científico; (ii) benefícios do uso; (iii) descrição da planta; (iv) época e região para o plantio e (v) recomendações de uso. As respostas escritas da atividade presencial seguiram um certo padrão a partir de informações técnicas disponíveis em sites da internet, entretanto a questão (v) sobre recomendações de uso rendeu diferentes abordagens: houve destaque sobre recomendações de plantio, e também para recomendações de uso culinário da planta. As respostas não foram analisadas com profundidade pois não foi a intenção deste trabalho. Em continuidade às atividades de pesquisa, foi elaborada uma página na internet acessada a partir de $Q R$ $C O D E^{4}$. A intenção era ter um local em comum para registro geral da escola e assim compor um histórico das atividades relacionadas à permacultura, e futuramente, gerar a interação com a horta construída.

$\mathrm{Na}$ categoria (b), que envolve aspectos conceituais, a proposta de aula pautouse na ideia de ciclo aberto e dinâmico, e tratou dos conceitos biológicos sobre tipos de plantas e noções de energética da fotossíntese; noções de cultivo de sementes e mudas; diálogos sobre o porquê da construção da horta na escola e a importância dessa ação envolvendo a comunidade, trazendo aspectos históricos e socioambientais; discussões sobre resistência em materiais utilizados em estruturas de plantação, assim como reciclagem e reaproveitamento de materiais; conceitos matemáticos de proporção

4 QR CODE é a sigla para Quick Response Code, uma espécie de código de barras que pode ser lido por câmeras de celulares (que possuem o aplicativo de leitura) e demais aplicativos online. É um código que direciona o usuário para uma página na internet contendo informações específicas sobre determinado assunto. No caso deste trabalho, o QR CODE foi desenvolvido de forma individual para direcionar o leitor a informações sobre o desenvolvimento de atividades relacionadas à permacultura. 
entre a terra vegetal, areia e o substrato a ser utilizado, essa reflexão contribui para o conhecimento no aspecto do cultivo e a importância da rega para a manutenção da horta; e o espaçamento entre plantas. Assim, com esse trabalho procurou-se discutir o ciclo de energia partindo de algo local (a horta) e conectá-lo com o global. Essa perspectiva mostrava que as ações dinâmicas perpassam todo o estudo e que um ciclo fechado e estático está distante da realidade. A Figura 3 apresenta elementos discutidos nas categorias.

Figura 3. O engajamento dos estudantes e os conceitos científicos escolares

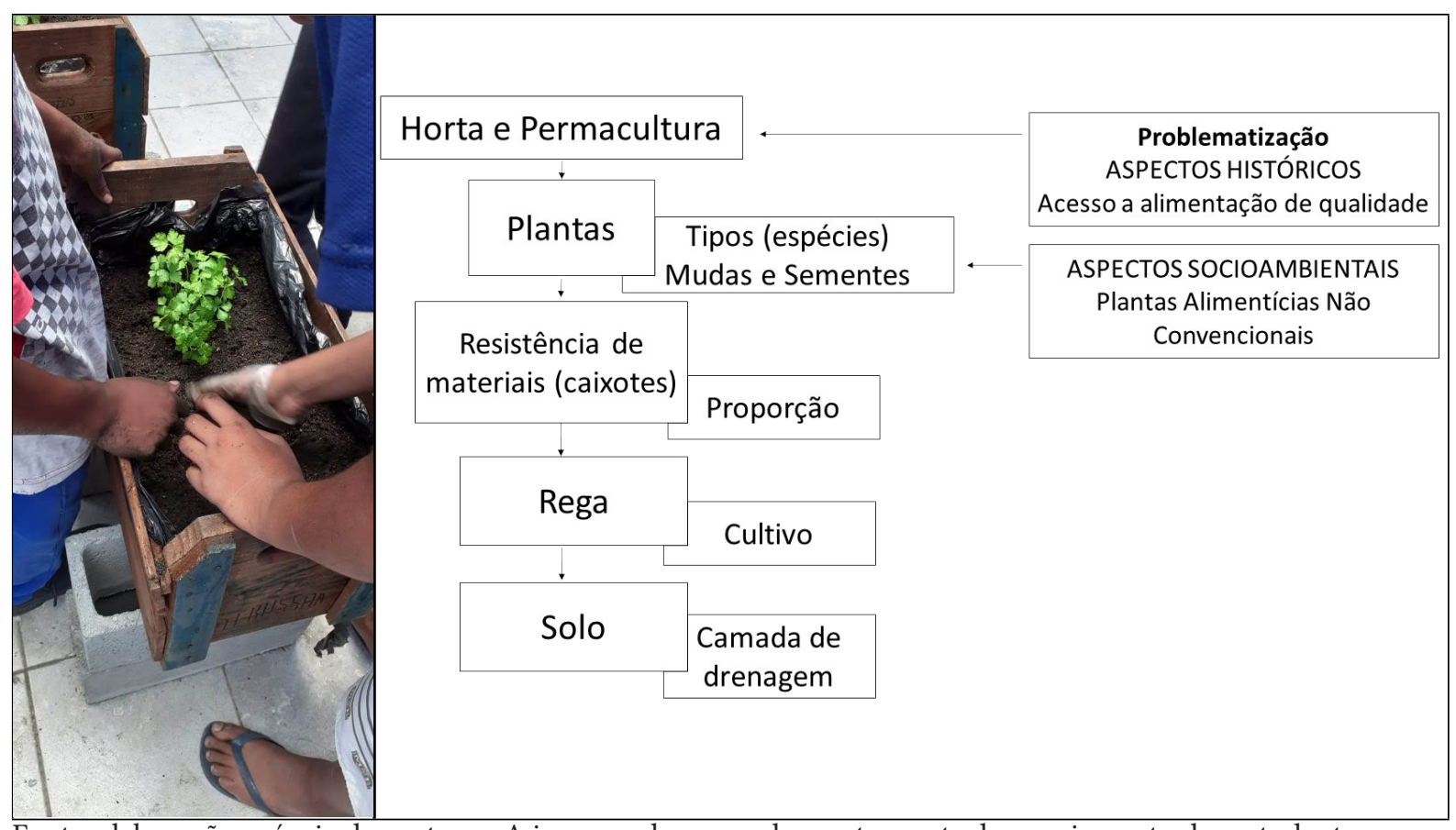

Fonte: elaboração própria dos autores. A imagem da esquerda mostra parte do engajamento dos estudantes, relacionado à categoria (a); a imagem da direita apresenta o percurso conceitual utilizado na proposta (Santos, C. S., et al., no prelo), relacionado à categoria (b).

\section{O processo de construção e aplicação da proposta de aulas remota - Células e sistemas}

Na categoria (a), que envolve aspectos de aproximação com a realidade, a intenção primeira foi restabelecer contato com estudantes e suas famílias após a interrupção das aulas presenciais, de forma que a coordenação e a direção da escola aderiram às ferramentas virtuais de aprendizagem, como a criação de um $B \log ^{5}$, em que foram postadas aulas, atividades e demais propostas curriculares das diversas disciplinas (biologia, química, física, ciências, educação física, entre outras); uso da plataforma google classroom; e comunicação por meio do aplicativo whatsapp. A proposta de aulas sobre Células e Sistemas contou com cinco reuniões remotas com as professoras, sem contato com estudantes nessa etapa. As decisões foram tomadas a partir das orientações dos professores. Nas reuniões remotas entre o GrECC e as professoras, além da reformulação

5 Blog - Ambiente Virtual de Aprendizagem. 
das ações e definição do conteúdo conceitual, surgiu a preocupação de elaborar propostas mais curtas e arquivos de tamanho reduzido para se adaptar às dinâmicas de envios pelo aplicativo whatsapp. Levou-se em consideração as possíveis adversidades relacionadas ao sistema remoto, elaborado de forma emergencial, considerando: a dificuldade de acesso à internet e limitação de dados e a restrição aos dispositivos eletrônicos (muitas vezes compartilhados entre mais de um usuário).

A primeira reunião remota determinou pontos importantes para a continuidade da parceria com a escola. Ocorreu nos meses iniciais da pandemia, permitindo contextualizar o cenário em que a escola e a comunidade estavam imersas, a saber: estudantes com acesso restrito a rede de dados e materiais para assistir aulas virtuais; professores com demanda para reajustar o plano de ensino e produzir tarefas remotas. A segunda reunião ocorreu entre os pesquisadores e a professora de ciências, havendo compartilhamento do plano de ensino e alinhamento de ideias quanto aos conteúdos conceituais a serem abordados nas propostas de aula. A terceira reunião ocorreu para compartilhamento do trabalho desenvolvido. Destaca-se o relato da professora sobre as dificuldades alunos encontradas naquele momento:

(...) os sextos anos está com um total de 109 alunos, teve muita transferência, as salas começaram com 35 alunos por sala! Agora as salas estão na média de 20 por sala. (...) Para gente consta como transferido, mas muitos não estão acompanhando o centro de mídias e não estão mandando as atividades, mas o ensino médio provavelmente terá muito abandono! (Diário do professor, 22 de Julho 2020)

As duas reuniões seguintes tiveram o mesmo caráter, ou seja, desenvolvimento das propostas de aulas, interação com a professora de ciências, a qual enviava o material aos alunos pelos grupos de whatsapp.

$\mathrm{Na}$ categoria (b), que envolve aspectos conceituais, a professora de ciências compartilhou o seu plano de ensino, ajustado para atividades quinzenais. Em equipe, decidiu-se por auxiliar na construção de propostas de aulas sobre o conteúdo curricular: "Células como unidade da vida", disposto na Base Nacional Comum Curricular (BNCC) (MEC, 2017), considerando aspectos do sistema e níveis de organização dos seres vivos. A proposta de aulas pautou-se então nos preceitos da complexificação do pensamento sobretudo no que diz respeito ao reconhecimento das partes que compõem um todo e as interrelações entre estas partes; as relações entre aspectos do micro e do macro e as ideias sobre sistemas; privilegiamos também abordagens próximas da realidade dos sujeitos e outras esferas do conhecimento, por exemplo, ao iniciar a proposta contextualizando ao momento da pandemia. Foram abordados conceitos da unidade temática Vida e Evolução (MEC, 2017) com aspectos da diversidade de seres vivos (unicelulares, pluricelulares, procariontes e eucariontes) e vírus; microscopia; relações dinâmicas entre os seres vivos e produtos de suas ações; níveis de organização dos seres vivos e reportagens trazendo produções científicas. Foram construídas quatro aulas organizadas em Momentos, a saber: Momento 1: contextualização a partir da 
atividade "Escreva uma carta para um estudante que vive em outro país contando sobre sua percepção da pandemia do Coronavírus aqui no Brasil. Explique como está a contaminação no seu bairro e como você se sente em relação a isso"; definição de ser vivo a partir da teoria celular; e organização das informações por meio de uma estrutura conceitual; Momento 2: respostas de estudantes sobre a interação entre vírus e células, introduzindo o tratamento de conceitos iniciais sobre diversidade de seres vivos (unicelulares e pluricelulares); abordagens sobre a interação entre bactérias e seres humanos, assim como aspectos sobre o produto de funcionamento desses organismos com a atividade de produção de iogurte; Momento 3: discussão sobre diversidade dos seres vivos (procariontes e eucariontes), abordando aspectos descritivos dos tipos de células e seus componentes - sistemas mais complexos, e atividade "Imagine que você está entrando em uma célula. O que você encontraria no seu interior?"; Momento 4: conceitos sobre níveis de organização dos seres vivos (micro ao macro), uso de uma reportagem sobre miniórgãos produzidos em laboratório para estudo sobre coronavírus; atividade final "Já se passaram alguns meses desde que a pandemia começou. Depois de todos esses momentos, escreva outra carta para esse seu amigo contando sobre coisas interessantes que você aprendeu.." Destaca-se que cada momento é finalizado com uma questão que promove discussões para a aula seguinte.

Também foram produzidos podcasts para cada um dos Momento de aulas, cuja intenção foi incentivar a autonomia, a partir de discussões e explicações de possíveis dúvidas que, por sua vez, poderiam auxiliar na interpretação dos conceitos estudados de modo remoto e promover interações entre os alunos e docentes (por exemplo, ao pensarem e discutirem o contexto de produção e os assuntos estudados). Autonomia que, segundo Freire (1996), expõe, dentre outros aspectos, como a compreensão dos condicionantes e a atuação sobre eles, de forma a garantir que elementos da própria realidade possam ser ferramenta para estímulo da criatividade e da curiosidade do educando. Para tanto, os áudios seguem uma sequência de acordo com o material escrito com objetivo de resgatar elementos e compor a ideia de construção do conhecimento. Foram elaborados seguindo os processos: elaboração de roteiro; gravação entre pares por meio de plataforma digital; edição pelo aplicativo Anchor; compartilhamento entre integrantes do GrECC para avaliação do conteúdo e qualidade do áudio; e disponibilização para uso. Destacam-se os elementos presentes nos áudios: introdução com apresentação dos participantes e da dinâmica de cada aula; explicações sobre o que será abordado, no sentido de contextualização dos conceitos; demais explicações para apropriação do material, como a respeito de links de acesso a materiais complementares ou às aulas do Centro de Mídias (SEDUC-SP, 2020). A Figura 4 mostra um recorte das propostas de aulas. 
Figura 4. Proposta de aulas remotas enviadas aos alunos pelo aplicativo whatsapp

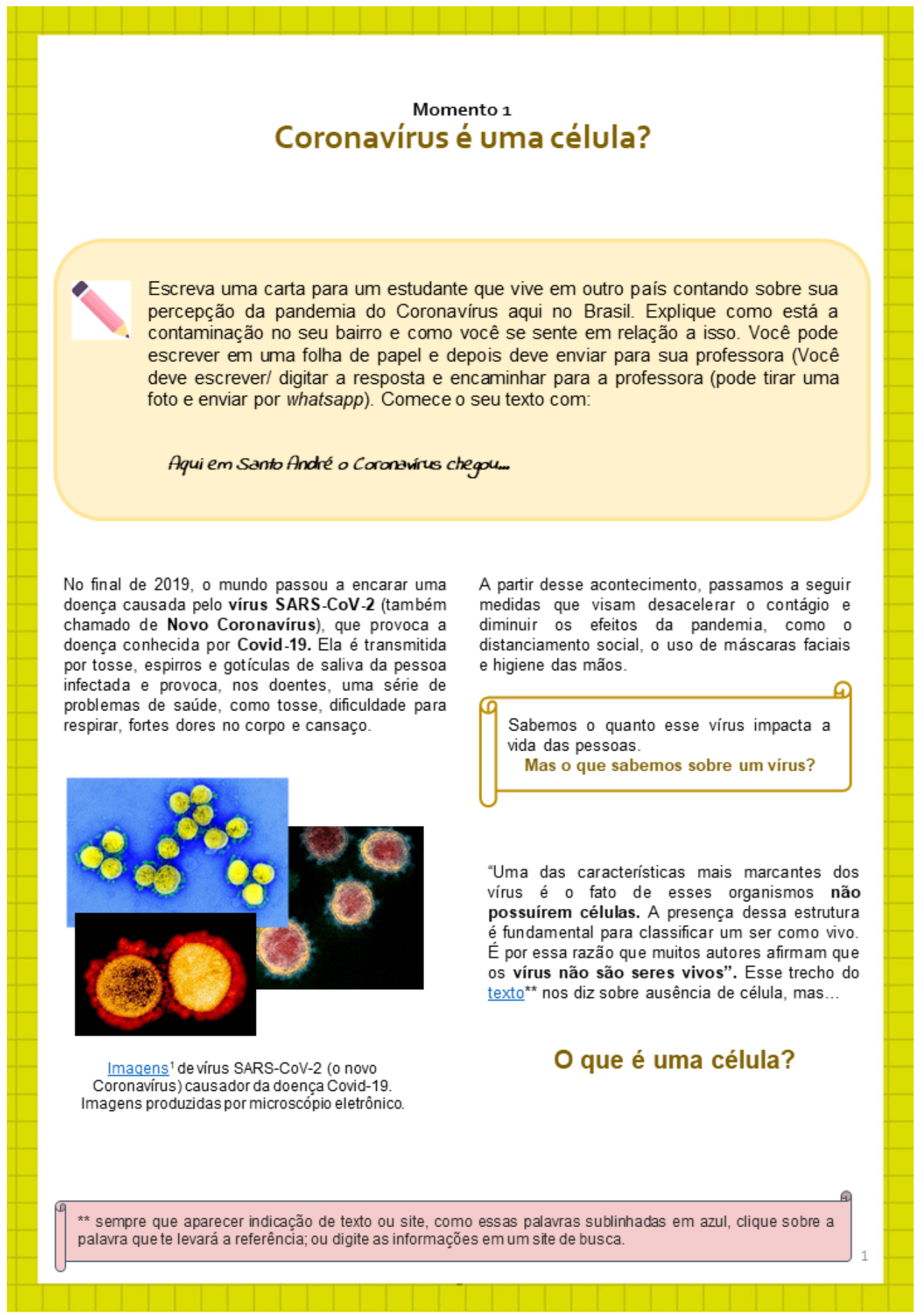

Fonte: elaboração própria dos autores. 
Figura 4. Proposta de aulas remotas enviadas aos alunos pelo aplicativo whatsapp (continuação)

\section{De que forma as células se organizam?}

$\mathrm{Na}$ aula anterior você teve que pensar e responder a seguinte pergunta: Vírus podem invadir as células? Como fazem isso? Algumas das respostas foram:
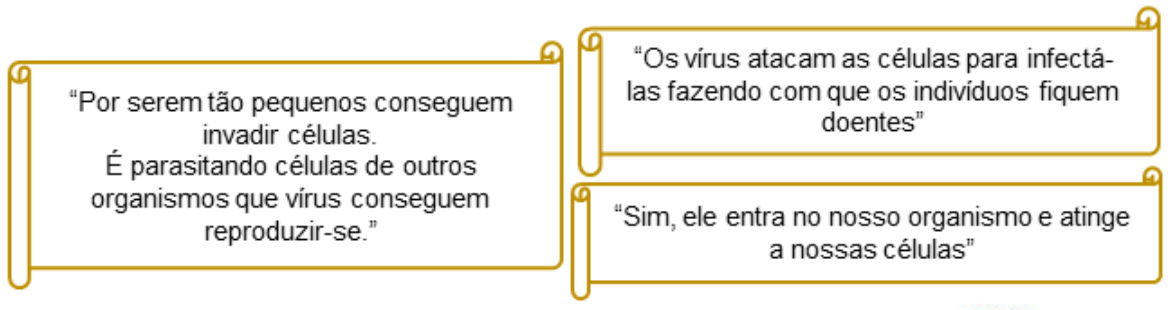

Os virus invadem células, sejam elas células de animais, células de plantas e até mesmo células de bactérias. $\mathrm{Na}$ imagem $^{\star *}$ ao lado estão algumas representações de diferentes tipos de virus (em azul está uma representação do vírus atacando a bactéria):

- o Influenza é o vírus da gripe, que ataca células animais;

- HIV é o virus da Imunodeficiência humana, causador da doença AIDS em humanos:

- Bacteriófago é o tipo de vírus que ataca células de bactérias

$\mathrm{Na}$ imagem abaixo vemos o coronavírus (em rosa) infectando células humanas.

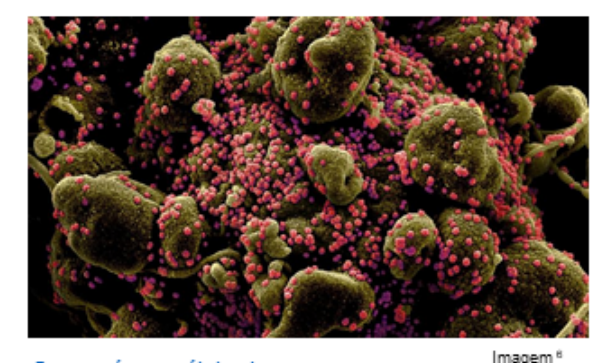

Coronavirus e células humanas

Imagem *

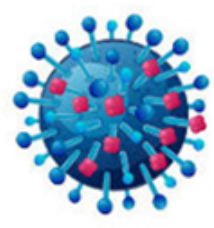

Influenza
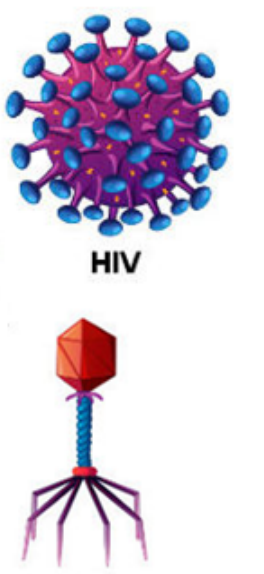

Bacteriófago Imagems

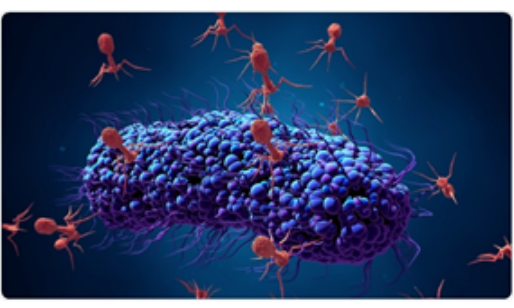

Bacteriófagos (emvermelho) atacando Imagem? bactéria (em azul)

** sempre que aparecer indicação de texto ou site, como essas palavras sublinhadas em azul, clique sobre a palavra que te levará a referência; ou digite as informaç̃ôes em um site de busca.

Fonte: elaboração própria dos autores. 


\section{O que esses processos de construção e aplicação de aulas em contextos distintos contemplaram da criticidade e complexidade?}

Ainda que os aspectos de criticidade e de complexidade foram indicados ao longo da análise do processo de produção e aplicação das propostas de aulas, nos parece fundamental delimitar as suas possíveis contribuições quando consideramos as distintas realidades vivenciadas em momentos tão peculiares como os atuais. Com base nisso, ao menos dois aspectos, que se referem aos resultados, podem ser evidenciados. Assim, a proposição de aulas mais crítica e complexa pode ser viável ao: (i) estabelecer maiores aproximações com as realidades dos estudantes e promover o engajamento e autonomia dos sujeitos em espaços que vão além da escola (no caso remoto, os usos críticos dos meios virtuais; no caso presencial, a aproximação com a comunidade); e (ii) contemplar os contextos socioeconômicos e os conceitos escolares pautados em abordagens mais abertas e dinâmicas.

Com base em (i), que se refere a aproximação aos aspectos de organização das atividades considerando os seus contextos e realidades, as reuniões presenciais mostraram um intenso diálogo para atender as demandas da escola, por exemplo, ao incluir as opiniões da merendeira e do grêmio escolar e contar com a ajuda da comunidade local, mostrando que a comunidade local teve participação efetiva na construção das aulas. Isso evidencia o papel transformador da escola que, segundo Freire (1968), precisa promover mudanças na visão de mundo, tanto dos estudantes quanto da comunidade local e dos profissionais que nela atuam. Também foi notável a tomada de decisões realizadas em conjunto, por exemplo, na definição do orçamento inicial e na escolha do espaço que inclui a horta. Já as reuniões remotas inicialmente não ocorreram com alta frequência como nas presenciais, mas isso justifica-se pelo processo de adaptação das escolas. Nessas reuniões as decisões tomadas foram mais objetivas, incluindo, por exemplo, elaborar propostas curtas e arquivos de tamanho reduzido para se comportar às dinâmicas de envios por whatsapp e considerar as dificuldades enfrentadas pelos alunos como o acesso restrito à rede e aos dispositivos eletrônicos. Nota-se que em ambas as propostas, as reuniões tiveram aproximação com a Dimensão de Ensino-aprendizagem (Watanabe, 2021), ou seja, com a preocupação em trazer o diálogo e a tomada de decisões em equipe; em considerar as situações de risco e as incertezas que foram vivenciadas tanto no contexto remoto quanto presencial; e em promover a escuta dos sujeitos da escola e da comunidade (especialmente no contexto presencial). De forma geral, nota-se que tais ações contribuíram para haver um processo de educação democrática afastando-se de uma visão bancária, a qual, segundo Freire (1979) restringe o desenvolvimento próprio da consciência crítica que resulta na sua inserção no mundo.

Com base em (ii), que se refere ao que denominamos aspectos socioconceituais (inclusão dos contextos socioeconômicos a partir dos conceitos escolares, e vice-versa) que podem promover abordagens mais abertas e dinâmicas, foram contemplados os conceitos como escalas, ciclos, dimensões, sistemas etc.. Nota-se que essa proposta de 
aulas presencial privilegiou reflexões abertas pautadas no ciclo dinâmico. Nesse tipo de abordagem, os estudantes podiam contar com as orientações mais próximas tanto da professora quanto das pesquisadoras. Já a proposta de aulas remotas privilegiou o conceito de sistemas abertos e dinâmicos e a relação do micro e macro, que segundo Morin (2007) estimulam o desenvolvimento de pensamento complexo, estabelecendo inter-relações entre diferentes tipos de conhecimento, tal como também preconiza a Dimensão Epistemológica (Watanabe, 2021). Neste caso, as interações entre alunos e professoras e pesquisadoras apresentaram um tempo de resposta mais longo. Neste tipo de proposta privilegiou-se as aulas mais curtas (momentos limitados a duas ou três páginas) e a produção de podcasts a fim de esclarecer tanto os conceitos centrais estudados quanto a dinâmica de estudos. Nota-se que esses podcasts foram elaborados a partir da necessidade de se pensar em alternativas acessíveis, que concordam com a ideia de postura ética (Freire \& Freire, 2014), garantindo a seriedade do processo educativo e o espaço para o diálogo, ainda que num contexto pandêmico.

Ambas as propostas foram construídas a partir dos preceitos da aproximação à realidade dos sujeitos (Freire, 1967), da complexificação do pensamento (Morin, 2007) e considerando também as outras esferas do conhecimento (Garcia, 2004). Na perspectiva freireana, um exemplo seria o conceito de diferenciação entre vírus e célula, que apesar de ser abstrato, auxilia na compreensão do funcionamento do organismo e da interação com causadores de doenças, como a Covid-19, possibilitando a tomada de decisão frente às políticas públicas, decisões individuais para controle da pandemia, leitura crítica de reportagens ou mesmo na compreensão de conhecimentos não espontâneos presentes na realidade, que nesse ponto, englobam escalas microscópicas. E no caso da permacultura, a perspectiva freireana indica a tomada de consciência de modelos alternativos de produção alimentícia, evitando a exploração desenfreada de recursos humanos e naturais, assim como estabelece uma postura crítica ao instrumentalizar o estudante para produção de seu próprio alimento, sendo autor e transformador da sua realidade.

Ao envolver estratégias que abordam situações do mundo real, que abrangem problemas abertos, dinâmicos e complexos (Garcia, 2004) a partir de uma perspectiva problematizadora e dialógica (Freire, 1968), as propostas se aproximam dos preceitos também indicados na Dimensão Educacional (Watanabe, 2021). Quanto à participação dos alunos, na versão presencial, destaca-se que o processo da montagem da horta foi caracterizado pelo engajamento coletivo para buscar uma aprendizagem mais participativa, destacando empenho para conseguir doações da comunidade. O trabalho de pesquisa e divulgação também contou com um conjunto de ações, tais como: pesquisa na rede e questionamentos diretos aos professores, escrita individual, elaboração de relatórios e criação de $Q R$ code disponível na identificação da horta. Na versão remota destaca-se o engajamento mais pontual dos alunos, ou seja, nota-se que conseguiram participar da atividade e contaram com o apoio dos responsáveis. Isso se refletiu, por exemplo, na elaboração de cartas contando a condição de aprendizagem em época 
de pandemia e na produção de iogurte (essas foram sugestões presente na proposta de aulas). Evidentemente, que o número de retorno das atividades neste contexto foi bastante reduzido. Percebeu-se que, em ambas as propostas os estudantes tinham a oportunidade de intervir na realidade, e em seguida, refletir sobre sua atuação. Assim, como salienta a perspectiva freireana, esse movimento entre ação e reflexão permite o distanciamento crítico, e com isso, reconhecer a tarefa complexa de perceber seu papel transformador e de sistematizar conhecimentos através de uma nova visão de mundo.

Como forma de ampliar e sistematizar os resultados encontrados, a Figura 5 traz as principais ideias e aspectos que podem contribuir para a promoção de aulas mais complexas e críticas, ou seja, indicam-se os parâmetros centrais da criticidade e complexidade obtidos durante a construção e aplicação das propostas de aulas remotas e presenciais.

Figura 5. Quadro com alguns parâmetros para construir aulas mais críticas e complexas

\begin{tabular}{|c|c|}
\hline \multicolumn{2}{|l|}{ Elementos da proposta de aulas } \\
\hline $\begin{array}{l}\text { Presencial } \\
\text { (Horta escolar e dinâmica dos ciclos) }\end{array}$ & $\begin{array}{l}\text { Remota } \\
\text { (Células e sistemas) }\end{array}$ \\
\hline $\begin{array}{l}\text { - Reuniões com intenso diálogo e ação para atender } \\
\text { as demandas da escola. Relatos que buscam melhorar } \\
\text { as condições estruturais da escola. } \\
\text { - Incorporar a participação da comunidade. Busca } \\
\text { por uma aprendizagem mais participativa. } \\
\text { - Decisões tomadas de forma mais negociada, em } \\
\text { conjunto e levando mais tempo. } \\
\text { - Busca pelo aprofundamento conceitual ao } \\
\text { considerar o volume e nível de detalhamento da } \\
\text { abordagem. } \\
\text { - Orientações presenciais tanto da professora quanto } \\
\text { dos pesquisadores. } \\
\text { - Engajamento dos alunos na construção da horta e } \\
\text { na produção dos relatórios e pesquisas realizadas na } \\
\text { redee nos livros didáticos sobre os conceitos tratados, } \\
\text { os questionamentos diretos aos professores, a escrita } \\
\text { individual e a produção de relatórios, a criação de } \\
\text { QRcode da planta da horta etc. }\end{array}$ & $\begin{array}{l}\text { - Reuniões com intenso diálogo, mas com baixa } \\
\text { frequência. Relatos dos problemas advindos da } \\
\text { pandemia. } \\
\text { - Decisões tomadas de forma mais objetiva: } \\
\text { elaborar propostas curtas e arquivos de tamanho } \\
\text { reduzido para atender a realidade dos alunos } \\
\text { (envios por whatsapp e acesso restrito à internet } \\
\text { e dispositivos eletrônicos). } \\
\text { - Contato limitado entre professor-aluno. } \\
\text { - Aulas limitadas aos Momentos, com duas ou } \\
\text { três páginas. Menor profundidade conceitual. } \\
\text { Produção de podcasts. } \\
\text { - Engajamento mais pontual dos alunos, mas } \\
\text { ainda com produções realizadas com apoio dos } \\
\text { responsáveis (elaboração de cartas e produção } \\
\text { de iogurte). } \\
\text { - Conceitos estudados: diversidade de seres } \\
\text { vivos (unicelulares, pluricelulares, procariontes } \\
\text { e eucariontes) e vírus; microscopia; relações } \\
\text { dinâmicas entre os seres vivos e produtos de } \\
\text { suas ações; níveis de organização dos seres vivos } \\
\text { e produção científica; dinâmica dos sistemas. }\end{array}$ \\
\hline
\end{tabular}

Fonte: elaboração própria dos autores. 
Figura 5. Quadro com alguns parâmetros para construir aulas mais críticas e complexas (continuação)

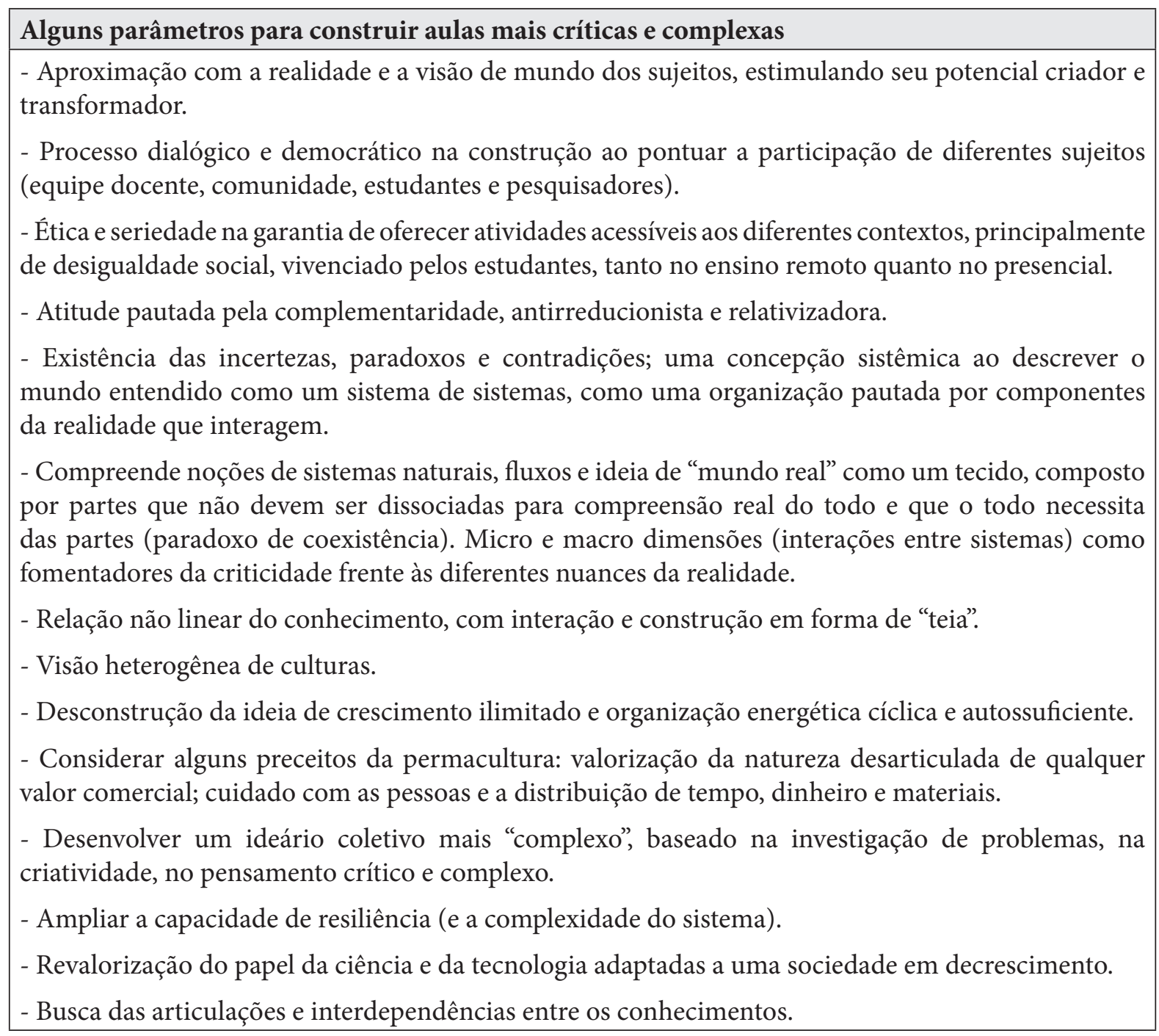

Fonte: elaboração própria dos autores.

\section{Conclusão e Considerações}

Nesse artigo analisamos o processo de construção de propostas de aulas no intuito de indicar parâmetros da criticidade e da complexidade que podem contribuir para a área em ensino de ciências e educação ambiental. Para isso procuramos explicitar as experiências no ensino presencial e remoto realizadas entre o grupo de pesquisa da universidade em parceria com a escola básica e a comunidade. Nota-se que o engajamento dos estudantes e da comunidade no ensino presencial foi elemento de destaque; em contrapartida, no ensino remoto a quase ausência de interação dos estudantes fez com que professores e pesquisadores encontrassem, ainda que limitados à suas realidades, novos caminhos para atingir a aprendizagem desejada. De antemão, destaca-se que em uma possível reconstrução dessa proposta, os aspectos de criticidade poderiam ganhar 
mais espaço considerando a apropriação dos territórios da escola e da comunidade local, assim como a consideração dos conhecimentos cotidianos para o desenvolvimento de uma visão de mundo mais crítica, por meio da apropriação da dinâmica ação-reflexãoação (Freire, 1979).

A reconstrução da proposta de aulas no contexto remoto, considerando preceitos da complexidade e da realidade dos estudantes, pode ser viável se formos capazes de estabelecer diálogos mais constantes com estudantes por meios virtuais dinâmicos; de propor uma regularidade de encontros entre docentes e estudantes; incentivar docentes na orientação e na mediação das propostas de aula; estimular o processo investigativo para promover, de fato, engajamento e autonomia num espaço que não se refere unicamente a escola; e considerar os contextos socioeconômicos para o desenvolvimento das atividades (por exemplo, no caso das hortas, reconstruí-las usando caixotes menores e materiais presentes nos contextos residenciais). Destaca-se ainda que as abordagens diretas em relação a vírus, vacina, discussões científicas e conflitos entre senso comum e ciência, podem ser incorporadas nas aulas para que os estudantes tenham capacidade de entender o que efetivamente estão vivenciando em suas realidades. Nessa perspectiva, Freire (1968) já apontava que

Nosso papel (como docente) não é falar ao povo sobre a nossa visão do mundo, ou tentar impô-la a ele, mas dialogar com ele sobre a sua e a nossa. Temos de estar convencidos de que a sua visão do mundo, que se manifesta nas várias formas de sua ação, reflete a sua situação no mundo, em que se constitui. A ação educativa e política não pode prescindir do conhecimento crítico dessa situação, sob pena de se fazer "bancária" ou de pregar no deserto. (Freire, 1968, p. 120).

Dos resultados encontrados, nos parece importante considerar o reconhecimento da realidade local para então situá-los num contexto mais global. Neste sentido, é fundamental estabelecer maiores aproximações com as realidades dos estudantes e promover o seu engajamento e autonomia em espaços que vão além da escola física. Ao tratar das estratégias, nos parece que um dos desafios é incorporar um processo de escuta dos sujeitos da escola e da comunidade, especialmente no contexto remoto de ensino. Isso significa que reconhecer as dificuldades locais dá margem para que os estudantes tomem decisões acerca de seus problemas e que possam buscar meios coletivos de soluções possíveis. Quanto aos aspectos conceituais, há de se incentivar uma perspectiva mais aberta e dinâmica, baseada também na criatividade e ação. Isso, tal como evidenciado nos nossos resultados, indicam a necessidade de contemplar os contextos socioeconômicos e os conceitos escolares que dão margem para uma formação mais aberta e dinâmica. Essa abordagem implica em incentivar reflexões relacionadas a diferentes esferas sociais, como política, cultural e econômica, permitindo articular questões como processos que levaram à pandemia ou questões de acesso à alimentação e recursos em períodos de crises socioambientais, políticas e econômicas.

Por fim, a experiência com as propostas de aulas aplicadas em cenários diferentes nos levou a uma reflexão sobre as variáveis dinâmicas e complexas presentes numa 
unidade escolar. Nos mostrou ainda que a educação voltada para uma formação mais crítica e complexa pode ocorrer tanto em condições presenciais quanto em condições remotas, desde que considerando suas particularidades. A experiência com a proposta de aula remota nos demonstra que há um potencial para se desenvolver atividades mais críticas nesses momentos de conflitos e incertezas.

\section{Agradecimentos}

Agradecemos ao Ministério da Ciência, Tecnologia, Inovações e Comunicações (MCTIC) e ao Conselho Nacional de Desenvolvimento Científico e Tecnológico (CNPq) (chamada 05/2019, processo nº440369/2019-3) e a Fundação de Amparo à Pesquisa do Estado de São Paulo (Fapesp) (processo n²018/19136-3).

\section{Referências Bibliográficas}

Beck, U. (2010). Sociedade de Risco. Editora 34.

Calafell, S. G. \& Banqué, M. N. (2017). Caracterización de las concepciones de complejidad de un grupo de investigadores de la educación ambiental. Enseñanza de las ciencias: revista de investigación y experiencias didácticas, 35(1), 53-69. https://raco.cat/ index.php/Ensenanza/article/view/319568

Costa, F. M. O. (2019). Problematizando os trajetos das alunas e dos alunos até a escola: temas de interesse para as aulas de ciências. (Dissertação de Mestrado, Universidade Federal do ABC, Santo André, São Paulo).

Díaz, J. E. G., \& Watanabe, G. (2019). Menos pode ser mais: do decrescimento e descomplexificação à complexidade. Linhas Críticas, 25. https://doi.org/10.26512/ lc.v24i0.19699

Freire, P. (1976). Ação Cultural para a Liberdade e outros Escritos. Paz e Terra.

Freire, P. (2016). Conscientização. Tradução: Tiago José Risi leme. Cortez.

Freire, P. (1967). Educação como Prática da Liberdade (40ª ed.). Paz e Terra.

Freire, P. (1979). Educação e Mudança (37ª ed.). Paz e Terra.

Freire, P. (1996). Pedagogia da Autonomia (52. ed.). Paz e Terra.

Freire, P. (1968). Pedagogia do Oprimido (63a ed.). Paz e Terra.

Freire, P., \& Freire, A. M. A. (2014) (Org.). Política e Educação. Paz e Terra.

García, J. E. (2004). Educación ambiental, constructivismo y complejidad. Díada Editora, S. L.

García, J. E. (2021). Educación ambiental y Complejidad [vídeo]. SNEF 2021 https://youtu.be/g1xUqX-VqxY 
Jacobi, P. R. (2012). Educar na sociedade de risco: o desafio de construir alternativas. Pesquisa em Educação Ambiental, 2(2), 49-65. https://www.periodicos.rc.biblioteca. unesp.br/index.php/pesquisa/article/download/6142/4501/

Jacobi, P. R. (2005) Educação Ambiental: o desafio da construção de um pensamento crítico, complexo e reflexivo. Educação e Pesquisa, São Paulo, 31(2), 233-250.

Latouche, S. (2009). Pequeno tratado do decrescimento sereno. WMF Martins Fontes.

Leff, E. (2009). Globalização e Complexidade. In Saber ambiental: sustentabilidade, racionalidade, complexidade, poder (pp. 416-445). Vozes.

MEC (Ministério da Educação) (2017). Base Nacional Comum Curricular. http:// basenacionalcomum.mec.gov.br/images/BNCC_EI_EF_110518_versaofinal_site.pdf

Mollison, B., \& Slay, R. M. (1998). Introdução à Permacultura (Tradução de André Luis Jaeger Soares). MA/SDR/PNFC.

Moraes, R., \& Galiazzi, M. C. (2007). Análise Textual Discursiva. Unijuí.

Morin, E. (2007). Introdução ao pensamento complexo ( $3^{a}$ ed.) Sulina.

Porlán, R., \& Martín, J. (1997). El diario del profesor. Díada Editora.

Ribeiro, R. A., \& Kawamura, M. R. D. (2014). Educação Ambiental e Temas Controversos. Revista Brasileira De Pesquisa Em Educação Em Ciências, 14(2), 159-169. https:// periodicos.ufmg.br/index.php/rbpec/article/view/4358

Rodríguez-Marín, F. Fernández-Arroyo, J. Y., \& Díaz, J. E. G. (2015). El huerto escolar ecológico como herramienta para la educación en y para el decrecimiento. Investigación en la Escuela, (86), 35-48. https://revistascientificas.us.es/index.php/IE/article/view/6800

Santos, C. S., Carvalho, F., Freitas, D., Watanabe, G. (no prelo). As hipóteses de transição num percurso temático complexificado sobre questões socioambientais: o exemplo da horta escolar. Revista de Educación Ambiental y Sostenibilidad.

SEDUC-SP (2020). Centro de Mídias do Estado de São Paulo. https://centrodemidiasp. educacao.sp.gov.br

Watanabe, G. (2021). As contribuições dos aspectos da complexidade para um ensino de física mais crítico. Revista Brasileira de Ensino de Física, 43(Suppl. 1), e20200416. https:// doi.org/10.1590/1806-9126-rbef-2020-0416

Watanabe-Caramello, G., \& Kawamura, M. R. D. (2014). Uma educação na perspectiva ambiental crítica, complexa e reflexiva. Revista Brasileira de pesquisa em educação em ciências, 14(2), 255-264. https://periodicos.ufmg.br/index.php/rbpec/article/view/4366 World Health Organization (2020) Timeline: WHO's COVID-19 response. https://www. who.int/emergencies/diseases/novel-coronavirus-2019/interactive-timeline 


\section{Fabrício Masaharu Oiwa da Costa \\ Universidade Federal do $A B C$ Santo André, São Paulo, Brasil fabricio.masaharu@ufabc.edu.br}

\section{Carla Sarmento Santos}

Universidade Federal do $A B C$ Santo André, São Paulo, Brasil carla.santos@aluno.ufabc.edu.br

${ }^{-}$Giselle Watanabe Universidade Federal do $A B C$ Santo André, São Paulo, Brasil giselle.watanabe@ufabc.edu.br

Editora Responsável

Stefannie Ibraim

Manifestação de Atenção às Boas Práticas Científicas e de Isenção de Interesse

Os autores declaram ter cuidado de aspectos éticos ao longo do desenvolvimento da pesquisa e não ter qualquer interesse concorrente ou relações pessoais que possam ter influenciado o trabalho relatado no texto. 